\title{
A Pragmatic Study of Swearing Objects and Expressions in Jordanian Arabic
}

\author{
Alaeddin Abdullah Banikalef \\ School of English Language and Literature, Faculty of Arts and languages \\ Jadara University, Jordan \\ E-mail: alaeddin@jadara.edu.jo
}

Received: May 5, 2020

doi:10.5296/ijl.v12i3.17148
Accepted: June 22, 2020

Published: June 29, 2020

URL: https://doi.org/10.5296/ijl.v12i3.17148

\begin{abstract}
This research paper aims at exploring the swearing objects and expressions that are used in Jordanian Arabic, particularly in the Mafraq Governorate. This study provides foreigners with enough information on swearing objects and expressions in the Mafraq Governorate. The stratified sample which allows selecting a separate simple random sample from each population stratum was applied in the current research. Questionnaire and interview method were employed in this study. The study found that Jordanians in Mafraq Governorate use fifteen swearing objects, including swearing by imaginary custodians as a unique swearing object for this area of Jordan. Various swearing expressions are used when people in Mafraq swear by these objects. The research paper concludes that there are differences in the percentage of using swearing objects between Mafraq Governorate and other northern parts of Jordan. The research paper recommends a new study of swearing objects and expressions in the whole of Jordan. A comparative study of swearing objects and expressions between Jordan and a certain western country, particularly a native English country is recommended.
\end{abstract}

Keywords: Speech acts of swearing, Swearing objects, Swearing expressions, Jordanian Arabic, Mafraq governorate

\section{Introduction}

Humans interact with each other in everyday life. They intend to share information and express their feelings and thoughts. They do not only use written and spoken forms of language for communication but they also use non-linguistic styles (e.g. facial expressions, body language) (Moaveni, 2014). 
Speech act theory investigates how to use language concerning the context in which it occurs the attitude of the speakers (action) and the influence of the language to the hearer. The pioneers of speech act are Ludwig Wittgenstein and J. L. Austen ( Al-Adaileh, 2007). Wittgenstein is the philosopher who assumes that the meaning of language relies on its actual usage. It is Austin who classifies the basic terms and areas of speech acts as locutionary, illocutionary and perlocutionary acts. These two are followed by some other philosophers to study speech act theory including John R. Searle. Searle (1976) says that any linguistic communication must have linguistic speech acts. He added that a speaker does not merely express meaning, but also express attitudes. Searle alters Austen's speech acts theory with some creative ideas. For example, he divides locutionary acts into utterance and propositional acts (Searle, 1976).

There are not enough studies of swearing objects and expressions carried out in the Jordanian society (Abdel-Jawad, 2000; Abdelbaset, 2009;Almutlaq, 2013). To be more specific, there is need to investigate the swearing expressions used in Jordanian Arabic. Such a study will fill a gap in related literatures. This study will provide foreigners with enough information of swearing in Jordan and particularly in the Mafraq governorate. This study is significant because it explores the various swearing expressions used by Jordanian Arabic in Mafraq Governorate in various contexts. Finally, this study is limited to the Bedouin dialect of the Mafraq Governorate, as this dialect is that of the majority in Mafraq area. The main goal of this study is to examine swearing expressions used by Jordanian Arabic in the Mafraq Governorate.

\section{Literature Review}

Based on the researcher's knowledge, there are few studies that examine the speech act of swearing in the Jordanian context (e.g., Almutlaq, 2013; Abdelbaset, 2009; Abdel-Jawad,2000; Banikalef \& Bataineh, 2017). All of these studies agreed that the speech act of swearing has been identified as an important part of everyday communication and formal ceremonies in Jordanian Arabic.

Almutlaq (2013) points out that oath are commonly used all over Jordan with various forms and types. These oaths are affected by some social factors so that oaths are shown in different ways. His research aimed at investigating the forms, terms, and expressions of swearing in vernacular of the Jordanian Arabic. Almutlaq classifies swearing into six terms as follows: First, the religious words are used to compose swearing terms like the words (Allah, God), (rab, lord) and (rasuul, messenger). Secondly, people use religious duties such as (Salaah, prayer) and (Haj, pilgrimage) to give swearing firmity and assurance to what they say or intend to do. A large number of people use the word (diin, religion) to compose other forms of swearing. Moreover, the word (çumr, age) is used in terms of swearing. Honor is considered as one of the most necessary values in the Arab world, so Jordanians use words like (sharaf, çirD, both mean honor) as swearing terms when they are linked with other words, for example (wsharafi, by my honor) and (wçirDummi, by the honor of my mother). Furthermore, Almutlaq demonstrated that the word (Halaf, swearing) as in (Hallaftakbillah, 
"I ask you" to swear by God) is also used in colloquial Arabic of Jordan to have terms of swearing. Besides the above terms of swearing, Jordanians swear by miscellaneous terms.

In order to find out the effect of gender constellations on the usage of swear words, Bayoumi ( 2017) investigated 154 female students responded to the study online survey and 6 of the questionnaire respondents participated in the follow-up interviews. Findings showed that female participants used swear words less frequently than males of the same speech community, yet equally offensive.

Fazeli (2019) prepared socio-linguistic and cultural study of swearing in Iraqi Arabic. The study investigated swearing in the sense of oath taking since it is not an alien concept in Iraqi daily life. The researcher analyzed the corpus of 100 Iraqi interlocutors. Findings confirmed that swearing is a linguistic behavior that is adopted in daily conversation in all speech communities. Data analysis also showed that Iraqis tend to use conversational swearing to preface nearly all types of speech acts.

\section{Method}

This is a quantitative study on swearing expressions that are used in real life situations. The current study is applied to the Mafraq governorate population. Mafraq is one of the twelve Jordanian governorates. It is located in the north-east part of the country to cover an area of about 26551 square kilometers, which represents $29.9 \%$ of the whole Jordanian area. According to the 2015 census, the estimated population of Mafraq governorate is about 551500 and that is $5.8 \%$ of the population in Jordan. The population in Mafraq who mostly speak Jordanian Arabic in Bedouin dialect is divided into 284300 (51.5\%) males and 267200 $(48,5 \%)$ females (Statistics, 2018).

A stratified sample was applied in the current research. This type of sampling allows the selection of a separate simple random sample from each population stratum (Mugo, 2002). The population is divided into three variables: gender, age, and level of education. The percentage that each variable represents in the whole population is taken into consideration while the sample is selected randomly. This type of sampling is also called random sampling technique with placement (Barreiro \& Albandoz, 2001). The sample of the questionnaire consists of 1000 Jordanians from the Mafraq governorate.

Questionnaire is employed in the current study because this instrument allows control over the contextual variables that appear in the situational description ( Aufa, 2014). Srivastava \& Hopwood, (2009) claimed that the questionnaire is not enough to collect data because "we cannot observe feelings, thought, intentions, and behavior". They added that "we have to ask people questions about those things". Consequently, an interview with three questions was also performed in the current study to reduce the limitation and disadvantages of using the questionnaire. Based on the researcher's knowledge, all the objects that Jordanians swear by are included in the questionnaire with a clear example for each of them. The objects and the examples of swearing are taken from the previous Jordanian studies as well as the Iranian study by (Aliakbari, Heidarizadi, \& Mahjub, 2013) and then modified in line with Jordanian society, in general, and with Mafraq community in particular. It is acceptable for the 
participants to add other objects they swear by and to mention any swearing expressions they use when they swear by these objects. The questionnaire is translated into Arabic and English. The interview is designed to elicit some extra data on new swearing objects and expressions. Data was analyzed in the form of tables through appropriate methods and instruments of statistics. The main goal of the current study is to find out the frequency of using various swearing objects and expressions in Mafraq Governorate. Because of that, the participants' answers were analyzed in a suitable way to achieve this goal. After collecting the data, the SPSS program was used to compute the statistics by.

\section{Findings and Discussion}

\subsection{Swearing Objects and Expressions}

As explained in the literature review, swearing has two main meanings. One of them is mostly used and understood in the Jordanian Arabic culture. It is "the act of adding a linguistic formula to what one says or does as a solemn or a formal appeal( to God ( or to a deity or something held in reverence or regard) in witness to the truth of the statement or binding character of a promise or undertaking" (Abdel-Jawad, 2000). The second meaning which is usually used in western culture refers to the bad language used to express anger and surprise (Abdel-Jawad, 2000). Arabic societies nowadays aren't only swearing by religiouexpressions, butbut they also swear by various objects and use unlimited swearing expressions. The data analysis shows the swearing objects and their percentage in the Table 1.

Table 1. Distribution of swearing objects, frequency, and percentage

\begin{tabular}{llll}
\hline No. & Object Sworn by & Frequency & Percentage \\
\hline $1-$ & Allah and Allah's Attributes & 401 & $40.1 \%$ \\
\hline $2-$ & Prophets and Messengers & 93 & $9.3 \%$ \\
\hline $3-$ & Divorce & 69 & $6.9 \%$ \\
\hline $4-$ & Family and Relatives & 66 & $6.6 \%$ \\
\hline $5-$ & Holy Books & 61 & $6.1 \%$ \\
\hline $6-$ & Body Organs & 49 & $4.9 \%$ \\
\hline $7-$ & Moral Values & 45 & $4.5 \%$ \\
\hline $8-$ & Food Items & 44 & $4.4 \%$ \\
\hline $9-$ & Important Dates & 42 & $4.2 \%$ \\
\hline $10-$ & Important Places & 35 & $3.5 \%$ \\
\hline $11-$ & Important People & 34 & $3.4 \%$ \\
\hline $12-$ & Miscellaneous & 30 & $3 \%$ \\
\hline $13-$ & Animals & 22 & $2.2 \%$ \\
\hline $14-$ & Objects of the Globe & 9 & $0.9 \%$ \\
\hline Total & & 1000 & $100 \%$ \\
\hline
\end{tabular}

The table above shows that the most frequent swearing object is 'Allah and Allah's attributes' which includes 401 responses to represent $(40.1 \%)$ of the respondents, whereas the least used swearing object is 'objects of the globe' with only 9 responses forming $(0.9 \%)$. The data show 


\section{Ml Macrothink}

International Journal of Linguistics

ISSN 1948-5425

2020, Vol. 12, No. 3

that Jordanians in the Mafraq governorate relatively use many expressions for each of the swearing objects. The following subsections investigated each swearing object thoroughly.

\subsubsection{Allah and Allah's Attributes}

As illustrated in Table (1), Allah and Allah's attributes are the most commonly used swearing objects. They represent $(40.1 \%)$ of the whole sample. Jordanians in the Mafraq governorate use various swearing expressions when they swear by Allah and Allah's attributes. This is because these expressions are religiously acceptable in Islam. Almost all Muslims agreed that it is allowed in Islam to swear by Allah and Allah's attributes but to swear by the other swearing objects is forbidden. Here are some examples of swearing expressions by Allah and Allah's attributes: (wallah, by God). The word (Allah, God) is the most used component of swearing by Allah. Here are some examples:

1-wallah, (by God)

2-wallahiilçaDHiim, (by His Almighty)

3-qasaman billah, (I swear by God)

\subsubsection{Prophets and Messengers}

The two words "prophet" and "messenger" are respectively equivalent in meaning to the Arabic words (nabi) and (rasuul). Because Jordanian Arabic are mostly Muslims, they strongly appreciate all prophets and messengers. Muslims not only swear by Prophet Muhammad (PBUH) but also by all other prophets and messengers because Islam requires its followers to believe in all prophets and messengers. It is not allowed in Islam to disbelieve in any prophets or messengers. This supports Muslims frequent swearing by prophets and messengers, mostly by Muhammad (PBUH). Prophets and messengers are considered as reverent people, so Jordanians in the Mafraq governorate often swear by them. Swearing by prophets and messengers gets the second rank between all swearing objects $(9.3 \%)$. The following are some examples of swearing expressions with prophets' and messengers' names used by the participants:

1. wiHyatinnabi, (by the life of the prophet)

2. wiHyatirrasuul, (by the life of the messenger)

3. wiHyatmuHammad, (by the life of Mohammad)

Religious commitment is the main reason that encourages people to swear by certain objects (prophets, holy books) rather than others (miscellaneous, important people) (Almutlaq, 2013). Muslims are aware that swearing by any objects, including swearing by prophets is not acceptable in Islam except for swearing by Allah( Almutlaq, 2013), although people in Mafraq still swear by the prophets. The current study found that people in Mafraq commonly swear by prophets because they believed that this type of swearing points out to their Islamic personality rather than some other swearing objects such as animals and miscellaneous. 


\subsubsection{Divorce}

Divorce means the action or instance of legally dissolving a marriage. This swearing object is popular among Jordanian males. They usually use it to intensify their actions and promise. Divorce percentage comes in the third rank with (6.9\%). The Arabic word "Tallaaq" means divorce. Here are two examples of swearing by divorce:

1. çalayyiiTTalaaqwminshaarbiillaagheir 'amsaHfiikil'arD, (I swear by the divorce of my mustaches I will wipe the floor with you)

2. çalayyiiTTalaaqillaatitghaddaa 'çndi, (I would divorce my wife if you didn't have lunch with me)

\subsubsection{Family and Relatives}

Relatives are people connected by blood or affinity. In his book (1999), His Highness Prince Ghazi Bin Muhammad says that tribal societies have integrated relationships within their families and relatives. This principle is so popular in Arabic societies, especially Bedouins. Muhammad (1999) investigates the nobility of the Bedouin tribes of Jordan. He considers family relationships in Bedouin communities to be full of virtues.

Like all Jordanians, people in Mafraq belong to conservative families (Muhammad, 1999). The population in Mafraq looks at family and relatives with high dignity and reverence. This encourages them to swear by their family members and relatives. Some participants point out that swearing by family members, particularlyfemales, are females are sometimes considered stronger than swearing by religious objects like holy books. They continue that when someone swears by the females of their family, you should believe this public type of swearing. Swearing by family and relatives represents $(6.6 \%)$ of the whole data. Here are three examples of this common type of swearing:

1. wiHyaatiwlaadi (by the life of my children),

2. wsharafummi (by the honor of my mother)

3. wraHmit 'abuui (by the mercy that encircled my father)

\subsubsection{Holy Books}

The holy book is the sacred book belonging to a certain religious community or political groups, for example, the Bible is the holy book of Christians and Quran for Muslims. It is obligatory in Islam to believe in all holy books like Quran, Bible, etc. To disbelieve in any of the holy books is unacceptable in Islam. Jordanians in the Mafraq governorate swear by holy books. Muslims consider this type of swearing as a kind of reverence and dignity for these books, although, it is not allowed in Islam to swear by holy books (Fontaine, 2018). Population in the Mafraq governorate mostly uses the words (quraan, musHaf, kitaabillaah, all means the Quran for Muslims) in their swearing expressions. Swearing by holy books represents $(6.1 \%)$ of the overall data. Here are two examples of swearing by holy books:

1-wilquraan, (by the Quran) 


\section{Macrothink}

2-wilmusHaf ishshariif, (by the honorable MusHaf).

\subsubsection{Body Organs}

Arabic people are proud of some parts of their bodies for example mustaches, arms and braids (Abdelbaset, 2009). These body organs are seen as symbols of manhood, strength, honor, beauty, etc. The population in Mafraq believes that swearing by these organs is related to cultural values inherited from the past. This type of swearing represents (4.9\%) of the overall sample. Participants mention some examples like:

1-minshaarbi, (I swear by my mustache)

2-wiHyaat halliHya (by the life of this beard)

The current study shows that it is rare for the population in Mafraq to swear by their body organs such as (leg) to refer to humiliation. Here are two examples from the collected data:

1-wiHyaatrijli(by the life of my leg)

2- wiHyaatshawaarbakwHaffaayti (by your mustaches and my shoes)

\subsubsection{Moral Values}

Moral values are the standards by which right and wrong defined. They can come from family, community, religion, ourselves or any other entity that influences the thoughts of the individual (Kaur, 2015). They are shared by the public in general, so if there is no agreement for moral values among communities, no moral values will be established. There are some moral values in Mafraq such as bravery, enthusiasm, and loyalty (Jarrar, 2013). The percentage of using moral values is $(4.5 \%)$ from the whole sample. Here are some quoted examples from the data collected:

1-wil 'amaana (by honesty)

2-çalaðimti, (on/upon my faith)

3-wsharafi, (I swear by my honor).

\subsubsection{Food Items}

Food items are valuable benefaction for Jordanians. Hospitality and generosity are among the most important values for Bedouins. Bread, salt, and water are the basic ingredients of most Jordanians' meals in the Mafraq governorate. Bedouins work hard to bring food, so they swear by food items (Ibrahim, 2012). Swearing by food items represent (4.4\%) and here are examples:

1-wiHyaat ilçiishwilmilHillibeinnaa, (I swear by the life of the bread and salt that we share).

2- wiHyaathanniçmah, (I swear by this benefaction) 


\subsubsection{Important Dates}

Muslims consider time as something religious for two reasons. First, it is forbidden in Islam to damn the time (Islam \& Wahra, 2015). Secondly, Islam insists that its followers should spend their time working, achieving and worshipping (Islam \& Wahra, 2015). These reasons encourage people to swear by important dates with (4.2\%) of the whole sample. Because the current study is applied in the Ramadan, Jordanians in Mafraq mention some examples of swearing by this holy month and the night of Decree as:

1-wiHyaatliilitilqadir, (I swear by the Night of Decree).

Jordanian community starts to move to secular life than a religious one (Abdelbaset, 2009), consequently, they swear by their birthdays, days of engagement and days of marriage such as:

1-wiHyaatiidmiilaadi, (I swear by my birthday)

2-wiHyaat halxutuubih, ( I swear by the day of my engagement)

The research shows that Jordanians in Mafraq, who are strongly connected with military service, swear by the day of Alkaramah (A battle between Jordanian and Israeli armies on $21^{\text {st }}$ March 1968 in Alkaramah village, Jordan Valley. The Jordanian army won the battle (Terrill, 2001) as one of the most significant achievements for Jordanians for example:

1-wiHyaat ilkaraamih, (by the day of Alkaramah Battle).

\subsubsection{Important Places}

Every community has special interests in some political, social, national or most religious places (Ababsa, 2011). These places can be inside or outside the country. Jordanians in Mafraq swear by such places as:

1-wiHyaat ilkaçbeh, (I swear by kaçbeh)

2-wiHyaatitraabhalwaTan, (I swear by the soil of Jordan)

3- wiHyaatilqudus, (I swear by the religious city of Jerusalem)

\subsubsection{Important People}

In every community, some people are considered/seen as significant symbols in a certain field like science or politics (A. Banikalef, Bataineh, \& Atoum, 2018; Choucair, 2006). The current research shows that it is a kind of appreciation to swear by their names. Jordanians in Mafraq swear by important figures like alive or late kings of Jordan for example:

1-wiHyaat jalaalitsayyidna, (I swear by His Majesty the king).

2- wiHyaatilmalikiHsiin, (I swear by the life of the late, King Husain)

This kind of swearing takes $(3.4 \%)$ of the sample. 


\subsubsection{Miscellaneous}

The current study found that Jordanians in Mafraq swear by anything around them, most especially, when discussing certain issues, and desperately trying to persuade the listener but do not find strong words for persuasion. Consequently, they swear by anything they see for example stone, home, wall, etc. The interview shows that this kind of swearing usually takes place in complicated conversations or disagreements. Blue collars, such as mechanics use this type of swearing (Abdelbaset, 2009). The percentage of miscellaneous swearing is (3\%). Here is an example of this type of swearing:

1-wiHyaat haSSuur, (I swear by this wall)

2- wiHyaathalburghi, (I swear by this screw)

\subsubsection{Animals}

Swearing by animals is mostly related to animals mentioned in the Holy Quran for example:

1- wiHyaatnaaqitSaaliH, (I swear by the she-camel of our master SaliH).

Mafraq community is mostly tribal (Muhammad, 1999). A long time ago, every tribe adopted an animal as a symbol for the tribe. This animal represents a certain positive feature like generosity (sheep), power (horse), etc. For example, Alharahsheh is a tribe that inhabited Mafraq a long time ago. This tribe adopted a yellowish horse which represents something positive for the members of this tribe ( Banikalef \& Bataineh, 2017). Data shows that the population in Mafraq swears by this horse while discussing/arguing certain issue with a member of Alharahsheh tribe, for example:

1-wiHyaat aSSafra, (I swear by your yellow horse).

This kind of swearing represents $(2.2 \%)$ of the overall sample.

\subsubsection{Objects of the Globes and Natural Phenomena}

The data collected shows that because Allah swears by the objects of the globe and natural phenomena in the Holy Quran, this encourages Muslims including the population in Mafraq to swear by these objects. After Arab Spring (A. Banikalef, 2019), Jordanians intensify their love for Jordan. They deeply understand that loyalty is crucial, particularly these days. Consequently, Jordanians in Mafraq swear by Jordan soil and sand. This type of swearing has a loyal connotation in addition to the religious one. Here are some examples:

1-wiHyaat itraabHalwatan, (I swear by the sand/soil of Jordan)

2-wiHyaat il'urdun, (I swear by Jordan)

3- wiHyaathaSSabaaH, (I swear by this morning)

This is the least frequent object of swearing with $(0.9 \%)$. 


\subsubsection{Imaginary Custodians}

There are some very old graves scattered in the villages of Mafraq governorate. The dead people there do not belong to any tribes of Mafraq. Old people in Mafraq retell stories and legends about the power of those dead people in the graves. Those dead people are claimed to bring benefaction and evils. The data collected shows that to get rid of custodians' punishment or evils, you need to sacrifice to them, visit their graves and swear by their names. Therefore, the population in Mafraq particularly old people swear by the names of those dead people or by their graves as:

1-wiHyaat qabirabuçyyaaT, (I swear by the grave of Abu IyaT)

2- wiHyaatilmheini, (I swear by Almhiini)

3-*wiHyaatabuðaablih, (I swear by the late, Abu Thablih)

*Abu Thablih is a very old grave for a religious man in Irbid, northern Jordan. Jordanians go there for religious tourism and medication)

In conclusion to section 4.2, the study shows that the population in Mafraq swear by fifteen objects including swearing by imaginary custodians. In addition, the significant Bedouin lifestyle in Mafraq encourages people to swear frequently by some objects of swearing than the other parts of Jordan do. However, various swearing expressions are used by each of the fifteen swearing objects.

\subsection{Analysis of the Objects Sworn by}

This subsection summarizes the percentage of the objects sworn by. Table (1) shows the percentage of frequency for each object, regardless of their variables. Table (1) shows that swearing by Allah and Allah's attributes represents (40.1\%) of the whole sample, prophets and messengers $(9.3 \%)$, divorce $(6.9 \%)$, family and relatives $(6.6 \%)$, Holy books $(6.1 \%)$, body organs $(4.9 \%)$, moral values $(4.5 \%)$, food items $(4.4 \%)$, important dates $(4.2 \%)$, important places $(3.5 \%)$, important people $(3.4 \%)$, miscellaneous $(3 \%)$, animals $(2.2 \%)$ and objects of the globe and natural phenomena $(0.9 \%)$. The current study found a new object of swearing. It is swearing by imaginary custodians.

The most popular swearing object is Allah and Allah's attributes take more than two-fifths of the whole sample. Divorce has a high percentage because males consider themselves more superior than females (Maaitah, Maaitah, Olaimat, \& Gharaeibeh, 2007; A. Banikalef, Maros, Aladdin, \& Al-Natour, 2015). Consequently, they swear by divorce to show the impression of superiority. All religious swearing objects, except for Allah achieve less percentage in previous studies in Jordan. That is because the community starts to shift from religious to secular life (Abdelbaset, 2009). As long as the community becomes more educated, the least they use religiously unacceptable swearing objects like prophets and Holy books.

\section{Conclusions}

In conclusion, Jordanians in Mafraq use fifteen objects of swearing including swearing by imaginary custodians and their graves. The frequency of using these swearing objects is quite 
different from previous studies of swearing in the Jordanian context. The current study found that the percentage of swearing by animals, people objects tend to be higher in this study than the previous studies, because of three reasons, First, Jordanian community is moving towards secular life rather than religious one. Secondly, Bedouins' lifestyle is relatively different from other Jordanian urban and rural lifestyles. The current study is related to the pragmatic field of linguistics for the following reasons. First, it reflects Jordanians' lifestyle in Mafraq. Secondly, illocutionary acts refer to the actions that people perform through their utterances (Mohammed, 2019). All swearing expressions that are used by current participants are related to illocutionary acts. These illocutionary acts reflect what people do in their daily lives. Finally, it is impossible to understand the exact intentions of uttering certain swearing expressions without being really aware of the pragmatic context in which such expressions are used. The study recommends a new study of swearing objects and expressions in the whole of Jordan to distinguish between how these swearing objects and expressions are applied in various Jordanian lifestyles. A comparative study of swearing objects and expressions between Jordan and a certain western country, particularly a native English country is also recommended.

\section{References}

Ababsa, M. (2011). Citizenship and Urban Issues in Jordan. In Cities, Urban Practices and Nation Building in Jordan (pp. 39-64). Paris: Presses de l'Institut français du Proche-Orient. https://doi.org/10.4000/books.ifpo.1724

Abdelbaset, H. (2009). A Socio-Linguistic Study of Oaths Produced by Interlocuters In Jordan Oath Expressions as Indicators of Cultural Variatio. Philadelphia University.

Abdel-Jawad, H. (2000). A Linguistic and Sociopragmatic and Cultural Study of Swearing in Arabic. Language, Culture and Curriculum, 217-240. https://doi.org/10.1080/07908310008666600

Al-Adaileh, B. (2007). The Speech Act of Apology A linguistic exploration of politeness orientation in British and Jordanian culture. The University of Leeds.

Aliakbari, M., Heidarizadi, Z., \& Mahjub, E. (2013). A Sociolinguistics Study of Conversational Swearing in Iran. International Journal of Linguistics, 5(3), 43-59. https://doi.org/10.5296/ijl.v5i3.3899

Almutlaq, H. (2013). A Sociolinguistic Study of Terms of Oaths in Jordanian Arabic. International Journal of Humanities and Social Science, 3(21), 225-228.

Aufa, F. (2014). The Use of Discourse Completion Task ( DCT ) as Explicit Instruction on Indonesian. EFL Learners' Production of Suggestion Acts, 2(6), 1-10.

Banikalef, A. (2019). The Impact of Culture and Gender on the Production of Online Speech Acts among Jordanian Facebook Users Ala' Eddin Abdullah Ahmed Banikalef. International Journal of Arabic-English Studies (IJAES), 19(2), 395-410. https://doi.org/10.33806/ijaes2000.19.2.9 


\section{I Macrothink}

International Journal of Linguistics

ISSN 1948-5425

2020, Vol. 12, No. 3

Banikalef, A. A. A., \& Bataineh, K. B. (2017). A Sociolinguistic Study of Speech Act Realization Patterns in Jordanians' Facebook Status Updates. International Journal of Linguistics, 9(3), 185-204. https://doi.org/10.5296/ijl.v9i3.11245

Banikalef, A., Bataineh, K. B., \& Atoum, M. (2018). Exploring facebook affordances in natural disaster: case study of the 2018 dead sea flash floods in Jordan. International Journal of Engineering \& Technology, 4(7), 5001-5006. https://doi.org/10.14419/ijet.v7i4.25862

Banikalef, A., Maros, M., Aladdin, A., \& Al-Natour, M. (2015). Apology strategies in Jordanian Arabic. GEMA Online Journal of Language Studies, 15(2), 83-99. https://doi.org/10.17576/gema-2015-1502-06

Barreiro, P. L., \& Albandoz, J. P. (2001). Population and sample. Sampling techniques. Management Mathematics for European Schools.

Bayoumi, M. (2017). When She Rhetorically Swears in Arabic: A Sociolinguistic Approach to Women's Swearing in a University speech community. The American University in Cairo School.

Choucair, J. (2006). Jordan's Stubborn Stability. Carnegie Endowment for International Peace, 2(2).

Fazeli, S. H. (2019). Nature of Swearing in Iraqi Arabic Society: A Sociolinguistic Study The Third International Conference on Current Issues of Languages, Dialects and Linguistics. In The Third International Conference on Current Issues of Languages (pp. 1-9). Iran-Ahwaz: LLLD. IR.

Fontaine, R. (2018). The Philosophical Foundations of Islamic Management. International Journal of Economics, Management and Accounting, 26(1), 207-227.

Ibrahim, E. (2012). Particularities of Bedouins' Social Life. HSSRP, I(1), 73-101.

Islam, R., \& Wahra, A. (2015). Time Management from an Islamic Perspective: An Exploratory Study. International Islamic University Malaysia, 1-20.

Jarrar, A. (2013). Moral Values Education in Terms of Graduate University Students' Perspectives: A Jordanian Sample. International Education Studies, 6(2). https://doi.org/10.5539/ies.v6n2p136

Kaur, S. (2015). Moral Values In Education. IOSR Journal of Humanities and Social Science (IOSR-JHSS), 20(3), 21-26. https://doi.org/10.9790/0837-20332126

Maaitah, R., Maaitah, H., Olaimat, H., \& Gharaeibeh, M. (2007, July). Arab Women and Political Development. Journal of International Women's Studies, 12, 7-26.

Moaveni, H. T. (2014). A Study of Refusal Strategies by American and International Students at an American University. Cornerstone. Minnasota State University, Mankato.

Mohammed, W. D. (2019). A Pragmatic Study of Oath Acts in English With Refernce to Arabic Oath| A Contrastive Study. Journal of Al-Frahedis Arts, 11(39), 619-631. 


\section{Macrothink}

International Journal of Linguistics

ISSN 1948-5425 2020, Vol. 12, No. 3

Mugo, F. (2002). Sampling in Research. Retrieved from https://profiles.uonbi.ac.ke/fridah_mugo/files/mugo02sampling.pdf

Muhammad, G. (1999). The tribes of jordan. Amman: RUTAB. Retrieved from https://freeislamiccalligraphy.com/wp-content/uploads/2018/04/Tribes-of-Jordan.pdf

Searle, J. R. (1976). A classification of illocutionary acts. Language in Society, 5(01), 1-23. https://doi.org/10.1017/S0047404500006837

Srivastava, P., \& Hopwood, N. (2009). A Practical Iterative Framework for Qualitative Data Analysis. International Journal of Qualitative Methods, 8(1), 76-84. https://doi.org/file:///C:/Users/emma.keller/Downloads/1169-13435-1-PB\%20(1).pdf

Statistics. (2015). Housing \& Population Census 2015 HKJ. Jordan.

Terrill, W. A. (2001). The Political Mythology of the Battle of Karameh. Middle East Journal, 55(1), 91-111.

\section{Copyrights}

Copyright for this article is retained by the author(s), with first publication rights granted to the journal.

This is an open-access article distributed under the terms and conditions of the Creative Commons Attribution license (http://creativecommons.org/licenses/by/4.0/) 